
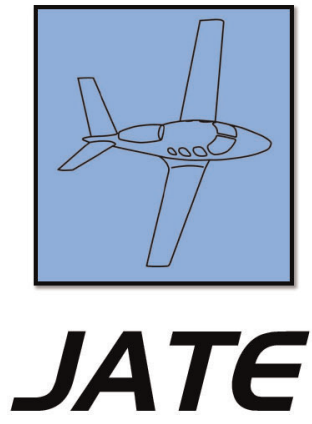

Journal of Aviation Technology and Engineering 10:1 (2021) 30-44

\title{
Service Quality and Passenger Satisfaction in Air Transportation in a Developing Economy: Evidence from Nigeria
}

\author{
Obioma R. Nwaogbe ${ }^{1}$, Innocent C. Ogwude ${ }^{2}$, Ejem E. A. ${ }^{2}$, and Pius A. ${ }^{3}$ \\ ${ }^{I}$ Nigeria Maritime University Okerenkoko, Warri \\ ${ }^{2}$ University of Technology, Owerri \\ ${ }^{3}$ Manchester Metropolitan University
}

\begin{abstract}
This study investigates the quality of service provided for air travel in Nigeria and the level of satisfaction of passengers with the service encountered. It does so by focusing on both the airports and the airlines as service providers. In that way, the study captures much of the effects of the organizational culture, employee behavior, and general norms which influence passenger attitudes. The SERVQUAL model was used in measuring the five dimensions of service. Domestic travel only was studied, with data obtained from well-structured questionnaires to evaluate perception-expectation gaps in airports as well as in airlines. The overall gap score of the Nigerian airports shows an average airport quality of service with a value of -1.8179 . This reveals that the perceived service quality is less than passengers' expectations in Nigerian airport service operations. In the same vein, the gap score of the Nigerian airlines shows an average airline quality-of-service gap with a value of -1.32 , which is generally low. This means that the passengers or customers of the airlines during the response period were expecting more service quality from the airlines in the country. The level of service at Nigerian airports needs to be improved so as to encourage passengers to use the airports and as well reduce many queues at baggage collection areas. The air travel industry is currently challenged in a recessed economy resulting in lower service standards, lower patronage, increased missed trips, flight cancellations, passenger complaints, and faltering loyalty. The findings of the study will, therefore, be useful to the managers of airports and airlines, the economic regulator of the aviation industry, and other stakeholders.
\end{abstract}

Keywords: Nigeria, airports, airlines, service quality, passenger satisfaction, SERVQUAL, domestic travel

\section{Introduction}

The air transport industry plays a pivotal role for millions of people in work, life, and leisure across the globe every year, especially for the areas of passenger and cargo movement from one geographical location to another. As articulated by Pius et al. (2017a), air transport is becoming more reliable, safe, and fast, compared with other modes of transportation, such as road, rail, and ship. The sector has contributed immensely to nations' economic growth, especially in emerging economies, through tax revenues, poverty alleviation by providing employment opportunities, and encouraging communities' 
integration (Nwaogbe et al., 2017a). Recently, a former director general of the Nigerian Civil Aviation Authority and a certified instructor with the International Civil Aviation Organization was quoted by one of the national newspapers, arguing that the air transport industry contributed an average revenue of $\$ 500$ million and $0.8 \%$ of the gross domestic product in 2015. Demuren (2017) pointed out that the demand for air transport service is growing on a yearly basis. Therefore, the importance of the air transport industry in national socioeconomic growth and technological advancement cannot be overstated, especially in a recession era. Oxford Economics (2015) and the International Air Transport Association (2015) maintain that Nigeria's air transport industry for the year 2015 supported approximately 159,000 jobs. This comprises 44,000 direct jobs; 64,000 indirect jobs, supported through the industry supply chain; and 51,000 jobs via its sector employees' spending and its supply chain. On performance indicators, the sector in 2015 recorded 15 million resident air travelers and about 181,000 tons of freight were moved to and from within the country.

Given the fact that air transport is the nation's gateway to the international marketplace, the quality of service in Nigerian airport transport is becoming a major topic for discussion by stakeholders (passengers, investors, government, and taxpayers). Airport Council International (2014) posits that air passengers are asking for more value for their ticket money. Improving and sustaining service quality can no longer be ignored by providers. This encourages private sector involvement, promotes a healthy competition within the industry, and adds positive value to the nation's economy (Nwaogbe et al., 2013). Service quality and customer satisfaction are two important factors in a competitive business environment like the air transport industry. This study focuses on passenger perceptions and expectations. More so, it is important to the industry to understand different measures that can be used in assessing service level and customer perception, so as to be able to meet passenger needs and expectations effectively. This can be done by understanding the gap that exists between expectation and perceived experience, for a better customer experience and loyalty.

This study aims to assess the overall service quality and passengers' satisfaction for some selected airlines and airports in Nigeria. It is imperative to understand how air passengers perceive service quality offered to them by service providers, and what are the key factors that influence their perceptions. The researchers' choice of using the SERVQUAL analytical tool for this study is based on the wider school of thought in the industry that SERVQUAL is among the best measurement tools and its effectiveness in capturing the level of service quality and air passenger satisfaction in a developing economy was fully considered and aligned with the research purpose and objectives. Thus, the model has been used by several authors in different contexts; nonetheless, the study adopts the SERVQUAL model looking at the average gap score that occurs between the perception and expectation of passengers at the airports in the study area. Factor analysis was also explored to determine those factors that have more effect on passengers' satisfaction as regards level of service and overall quality of service at airports. This study attempts to fill the gap in knowledge and contribute to the available experiential information on the emerging economy air transport network.

\section{Literature}

Service quality is an important factor in building customer trust, loyalty, satisfaction, and retention. It reduces operating costs and increases profitability. Service industry managers are under tremendous pressure to prove that their services are customer oriented and there is room for further improvement, to meet customer requirements, and loyalty for repeat patronage. It is only a satisfied customer that would likely come back for more business in the future, compared with a customer whose expectation was not met in the first encounter. Nwaogbe et al. (2017b) studied airline service quality in an emerging category one (CAT1) nation airport, focusing on Mallam Amino Kano International airport. In their study, the findings revealed that independent variables were influenced by airline quality of services in the study area. Service quality analysis outcome demonstrated that there is a statistical relationship between passengers' perception of reliability, comfortability, and affordability of the airline services at this airport.

Chilembwe (2014) examined service quality and passenger satisfaction at the Malawian airport and airline, using mix method for data gathering (face-to-face interviews and surveys) for managers and aviators. SERVQUAL dimensions were used to measure the satisfaction level of air travelers. The findings revealed that passengers were not satisfied with the level of service, and the perception gaps were established from the managers' viewpoints. However, the group's responses on service reliability were corresponding in some areas. Nevertheless, service reliability scored the lowest percentage recorded in the study. Ikeogu (2013) assessed that service quality is built on consumer perception, how they (customers) judged the quality of service offered to them by providers. Pabedinskaite and Akstinaite (2014) surveyed the quality of service at airports, using the SERVQUAL dimension to examine the level of service. The findings revealed that there is a correlation between airport quality of service and the level of service provided by the airlines. The researchers proposed a set of dimensions for measuring the quality of service provided by the airlines.

Measuring service quality level and passengers' satisfaction for airports and airlines has been discussed extensively by different authors over the years (Chao et al., 2013; 
Cronin \& Taylor, 2011; Ikeogu, 2013; Kirk, 2013; Kramer et al., 2013; Suzuki, 2014). Nevertheless, these studies do have something they all agreed upon: that there is no single accepted measurement for the airside and landslide in the industry for now. A diagrammatic illustration (Figure 1) of the five SERVQUAL dimensions, including expected service, perceived service, and service quality, is presented as the adopted conceptual framework for this paper.

Finally, several studies have been carried out in Nigeria on the quality of service using different models from the review of the literature, but this study will fill the gap by exploiting the SERVQUAL model based on six dimensions to examine the overall quality of service of the selected airports and airlines of the study area. The study will further explore the gap mean score that exists between customer expectation and perception of the overall quality of service for passengers and airport users of the study area. The study will also fill the gap by determining different gaps that exist between customers and the operators of airports and airlines and also derive policy implications on how to improve customer satisfaction in those selected airports in the study area. This study will also enhance market competition in the aviation industry through the policy implication that the airport and the airline operators can have more market share if the policy derived from the study were to be fully implemented by the stakeholders and the management of the airports and the airlines. Six dimensions of SERVQUAL are adopted from the SERVQUAL model (Kumar et al., 2009).

\section{Method}

In carrying out this quantitative research, various techniques of quantitative analyses with the use of statistical tools (descriptive and inferential) will be involved. SPSS version 24.0 and Excel package were used to run the analysis. Descriptive statistics were used, mainly involving the mean, standard deviation, skewness, and kurtosis in the data analysis. Factor analysis was employed to determine various factors affecting airport and airline quality of service. Furthermore, the SERVQUAL model was used based on variables that are related using factor analysis. The factor analysis enabled us to find out if the
SERVQUAL model is good for assessing service quality of airports and airline services in Nigeria.

Parasuraman et al. (1985) developed a conceptual model of service quality. This model works towards identifying the gaps that exist between the expectation and perception of customers' evaluation and factors that affect them. These are divided into five different gaps. They are: Gap 1: Consumer expectation-management perception gap; Gap 2: Management perception-service quality specification gap; Gap 3: Service quality specifications-service delivery gap; Gap 4: Service delivery-external communications gap; Gap 5: Expected service-perceived service gap. Furthermore, the dimensions we will focus on are related to the following six issues:

Tangibility (TA): physical facilities, equipment, and appearance of personnel.

Reliability (RL): ability to perform the promised service dependably and accurately.

Responsiveness (RN): willingness to help customers and provide prompt service.

Assurance (AS): knowledge and courtesy of employees and their ability to inspire trust and confidence.

Empathy (EM): caring for the individualized attention the firm provides to its customers.

Product (PR): service provided; how frequent and the quality of the service.

\section{Measurement}

In the measurement, the SERVQUAL model is used to assess consumers' expectations and perceptions as regards service quality in the Nigerian airports and airlines industry. Furthermore, both expectations and perceptions are measured based on a 7-point scale to rate the level of agreement or disagreement (1, strongly disagree; and 7, strongly agree), in which higher numbers indicate a higher level of expectations or perceptions. Perceptions are based on the actual service received in airports and by the airlines operating in the major city, selected airports, and airlines in the country, while expectations are based on past experiences and real information that the airport and the airline users received or expected to have in terms of service at the airports. Service quality scores are the difference between

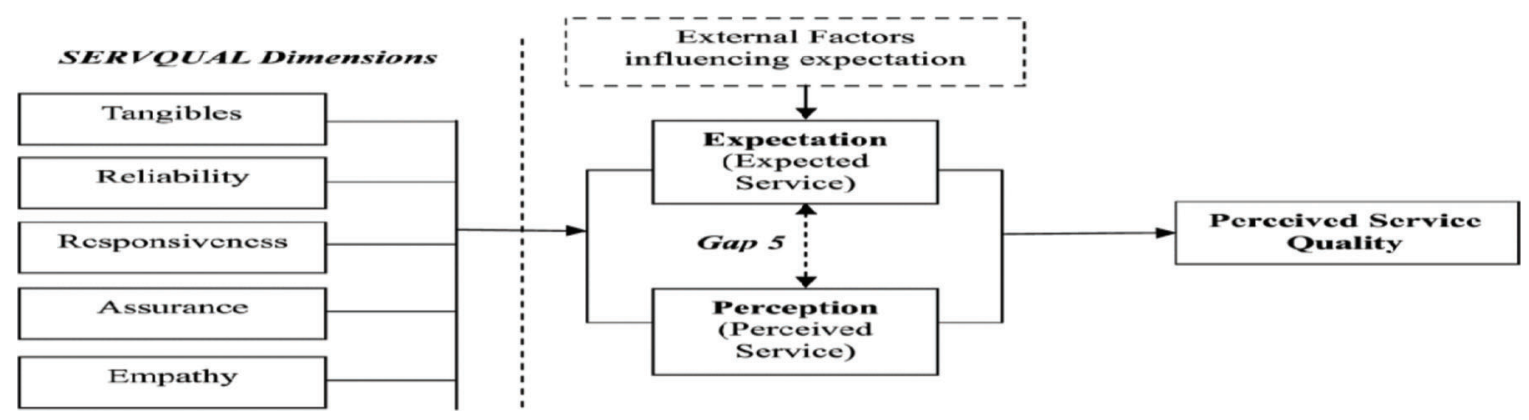

Figure 1. SERVQUAL model. Source: adapted SERVQUAL model (Kumar et al., 2009). 
Table 1

Summary of airports' mean gap scores/quality of service by passengers.

\begin{tabular}{|c|c|c|c|c|}
\hline Dimension & Statement & Expectation score & Perception score & Gap score \\
\hline \multirow[t]{4}{*}{ Tangibility } & TA1 & 6.59 & 4.34 & -2.25 \\
\hline & TA2 & 6.51 & 4.46 & -2.05 \\
\hline & TA3 & 6.56 & 5.31 & -1.25 \\
\hline & TA4 & 6.62 & 5.08 & -1.54 \\
\hline \multirow[t]{5}{*}{ Reliability } & RL1 & 6.32 & 4.51 & -1.81 \\
\hline & RL2 & 6.33 & 4.81 & -1.52 \\
\hline & RL3 & 6.35 & 4.74 & -1.61 \\
\hline & RL4 & 6.37 & 4.6 & -1.77 \\
\hline & RL5 & 6.46 & 5.04 & -1.42 \\
\hline \multirow[t]{4}{*}{ Responsiveness } & RN1 & 6.22 & 4.8 & -1.42 \\
\hline & RN2 & 6.32 & 4.93 & -1.39 \\
\hline & RN3 & 5.93 & 4.94 & -0.99 \\
\hline & RN4 & 6.18 & 4.94 & -1.24 \\
\hline \multirow[t]{4}{*}{ Assurance } & AS1 & 6.18 & 4.64 & -1.54 \\
\hline & AS2 & 6.31 & 4.82 & -1.49 \\
\hline & AS3 & 6.01 & 4.77 & -1.24 \\
\hline & AS4 & 6.05 & 4.86 & -1.19 \\
\hline \multirow[t]{5}{*}{ Empathy } & EM1 & 5.85 & 4.51 & -1.34 \\
\hline & EM2 & 5.77 & 4.74 & -1.03 \\
\hline & EM3 & 5.86 & 4.73 & -1.13 \\
\hline & EM4 & 5.89 & 4.58 & -1.31 \\
\hline & EM5 & 5.96 & 4.68 & -1.26 \\
\hline \multirow[t]{2}{*}{ Product } & PR1 & 6.11 & 4.45 & -1.66 \\
\hline & PR2 & 6.45 & 4.77 & -1.68 \\
\hline
\end{tabular}

Note. Average airport quality-of-service gap: -1.8179 .

the perception and expectation scores $(\mathrm{P}-\mathrm{E})$ with a possible range of values from -6 to +6 ( -6 means very dissatisfied and +6 means very satisfied). The quality score measures the service gap or the degree to which expectations exceed perceptions. The more positive the P-E scores, the higher the level of service quality leading to a higher level of customer satisfaction. Satisfaction and service quality are both treated together as functions of customers' perceptions and expectations. For service quality, when expectation and perception are equal, service quality is satisfactory. Table 1 shows the gap score of the quality of service in airports and airlines by customers.

Conducting research at airports with the passengers and users of the airports including the airlines, structured questionnaires were distributed at the selected airports and airlines operating in Nigeria (Nnamdi Azikiwe International Airport Abuja, Murtala Muhammed Airport Lagos, Akwa Ibom Airport, and Aminu Kano International Airport). The selected airports have a population of about 3.6 million passengers. The airlines undertaking domestic airline operations at the airports are: Air Peace, Allied Air, Aero Contractor, Azman Air, Dana, First Nation, Med-View Airline, Ibom Air, and Arik Air. A total of 180 questionnaires were distributed to passengers, airline operators, and airport staff to gather information. A one-week survey was carried out to examine the level of service at various screening points, check-in counters, and baggage collection areas. Out of the 180 questionnaires, 50 questionnaires were distributed to each of Nnamdi Azikiwe
International Airport Abuja, Murtala Muhamed Airport Lagos, and Aminu Kano International Airport, while 30 questionnaires were distributed to Akwa Ibom airport. Data were gathered through manual survey questionnaires, based on random sampling of airport and airline users. This study gathered a sample, which was carefully vetted and reduced to 150 respondents out of the population of several potential participants during the peak period, which provided useful data-central to the study. Amongst the 150 returned questionnaires, 22 were returned from Akwa Ibom Airport, 40 questionnaires from Nnamdi Azikiwe International Airport, 38 questionnaires from Aminu Kano International Airport, and 50 questionnaires from Murtala Muhammed Airport, Lagos. Statistical Package for the Social Science (SPSS) and Microsoft Excel were used for the analysis, and descriptive statistics were used for data presentation. Relationships and trends were displayed with tables and line graphs.

\subsection{Expectations and Perceptions of Airport and Airline Mean Gap Score Quality of Service by Passengers}

In this analysis, the airport passengers' expectations and perceptions were measured using a Likert scale, whereby higher numbers indicate a higher level of expectation or perception. Generally, consumer expectations exceeded the perceived level of service shown by the perception scores. This resulted in a negative gap score (perception minus expectation). According to Parasuraman et al. (1988), 
a study on consumer satisfaction, the study shows how common consumers' expectation exceeds the actual service perceived and this signified that there is always need for improvement. The services with the highest expectation scores were TA4 (physical environment of lounges/waiting rooms and that the others should be clean and tidy always) with a score of 6.62 and TA1 (the airport services should have up-to-date equipment (in terms of modern facilities) of the highest quality and value) with a score of 6.59. Employees of the airports should be well dressed and appear neat during their services, and this should also increase service quality by attracting customers (TA3) with a score value of 6.56 , while several expectations were scored from 6.51 for TA2, 6.46 score value for RL5 shows the highest score in reliability of service in Table 1 above. This result shows that the passengers/customers of the airport has high expectations from the airport, such as airports should keep records of passengers and the users of the airports accurately so that when there is an encounter with a passenger, the problems of such passenger can be traced. Furthermore, passengers should feel safe in their encounters with employees, service fare and quality should be affordable during peak and off-peak hours, and employees should be prompt in service delivery to passengers. The remaining scores of the expectation are shown in Table 1.

However, these scores are not very different from the scores of other questions and this implies that, generally, consumers expect a very high standard from airport operators. In the case of perception, the questions rated highest for actual services perceived were that the employees should be well dressed and appear neat in the airports so as to be attractive to passengers (TA3) with a score of 5.31; the physical environment of the lounges/ waiting rooms and other places should appear neat for passengers (TA4) with a score of 5.08; the airports should keep accurate records of passengers and airline employees should have the knowledge to answer passengers' questions (RL5) with a score of 5.04; employees of the airport are always willing to help passengers during terminal operation services (RN3) with a score value of 4.94; and that employees of the airports are never too busy to respond to passengers when they need attention (RN4) with a score of 4.94 .

In the gap analysis, the gap differences between expectation and perception were not much different from the various dimensions; instead, the scores of perceptions are lower than those of expectations. It is essential to consider the service gap that exists between passenger expectation and perception. For the gap scores, computation can be measured with a range of values between -6 and +6 (service quality and customer satisfaction). When the airport perception comes close to expectation, this implies that the higher the perceived level of quality, the more likely the customer will demand or choose to use the airport. This study shows various large gap scores of airport service quality. It shows that ideal airports in Nigeria need more modern equipment (TA1) with a gap score of -2.25 , Nigerian airports' physical facilities (building, waiting room, restroom, etc.) are needed for customer services (TA2) with a gap score of -2.05 , while the aspect of keeping promises made by airport operators at all times (RL1) gives a gap score of -1.81 . Moreover, airports should provide the services they promised customers and airport users when needed, which makes the airport a reliable airport (RL4) with a gap score of -1.77 . Finally, with regards to the good service quality provided by the airports (PR2), the gap score is -1.68 . Overall, the gap score of the Nigerian airports shows an average airport quality-of-service gap of -1.8179 . In general, these results indicated that respondents expect more from the airports.

\subsection{Gap Score Analysis}

The gap score results for the six dimensions show the possibility of determining how service users or passengers perceived the quality of service during operations at the Nigerian airports for the study area. Moreover, they identify service dimensions that show how satisfied the passengers are with airport services at the airports. Arguments were made by scholars (Parasuraman et al., 1985; Pius et al., 2017b) that the higher the scale of positive perception $(\mathrm{P})$, the lower the scale of a minus expectation score. Which means the higher the perceived service quality, the higher the level of customer satisfaction for the services offered by the providers. The gap scores for this study are based on the differences between the service users' perceptions and expectations. The researchers observed that perceptions of the service quality offered by the Nigerian airport operators fell short of expectations (gap score dimensions were mostly negative). Besides, the six dimensions' descriptive statistics were used in measuring the gap score assessment. The highest mean gaps were empathy (EM) with a score of -3.214 , followed by tangibility (TA) at -1.7725 and product service (PR) with an average score of -1.67 , while the lowest mean gap scores were responsiveness $(\mathrm{RN})$ at -1.26 , assurance (AS) with an average gap score of -1.365 , and reliability (RL) with an average gap score of -1.626 . A summary of gap score analysis shows that the perceived service quality is less than passengers' expectations in the Nigerian airport service operations.

Parasuraman et al. (1988) argued that the overall service quality can be measured by obtaining an average gap score of the SERVQUAL dimensions. Furthermore, to measure overall service quality efficiently as perceived by the passengers at various Nigerian airports, six dimensions of the SERVQUAL model were used to assess an optimum service at the airports. The management and alignment with the findings of Gronroos (1982), who proposed two main 
Table 2

Descriptive statistics for airport quality-of-service gap scores for the six dimensions.

\begin{tabular}{lcccccc}
\hline & $\begin{array}{c}\text { Average gap score Average gap score } \\
\text { for tangibility }\end{array}$ & $\begin{array}{c}\text { Average gap score } \\
\text { for reliability }\end{array}$ & $\begin{array}{c}\text { Average gap score } \\
\text { for responsiveness }\end{array}$ & $\begin{array}{c}\text { Average gap score } \\
\text { for assurance }\end{array}$ & $\begin{array}{c}\text { Average gap } \\
\text { for empathy }\end{array}$ \\
score for product
\end{tabular}

dimensions of service quality, technical and product dimensions, were added to the modified SERVQUAL model to reflect the technical dimension of service quality. The model is appropriate for measuring service quality in the airport industry, regarding the fact that service quality offered by the airport operators in Nigeria forms part of the core reason for passengers' satisfaction and continuing patronage decision making during operation. Table 2 shows the standard deviation scores distributed and consistent with the six dimensions. This suggested a wide range of opinions about the service quality among the respondents surveyed in this study (Pius et al., 2017a).

\subsection{Service Constants of Airports}

\section{Tangibility-TA}

With reference to tangibility (TA), the mean score is -1.7725 with a median gap score of -2.675 , while the standard deviation of the gap score is 0.6705 , indicating the spread of gap scores away from the mean. This dimension has the highest deviation, but it does show great deviation from the mean. The distribution is positively skewed with a value of -2.644 , which indicates that the figures have deviated more to the right. The kurtosis value was 12.786 , which means that there is a clustering somewhere away from the mean. This implies that the service users expected more than what they were getting from the providers.

\section{Reliability-RL}

In the aspect of reliability (RL), the result shows a mean of -1.626 , which means that service users (passengers) are not satisfied with the quality of services as shown by the reliability service dimension. It shows a standard deviation of about 0.4292, which means that the gaps are spread away from the mean. The median gap score for reliability is -1.6 . The gap distribution is positively skewed with a value of -2.0278 , indicating that the gap scores are deviated toward the right at the mean, and clustered close to the mean with a kurtosis value of -6.443 .

\section{Responsiveness-RN}

On average, customers are not satisfied with the level of services offered by the airport operators, with a gap of -1.26 for the responsiveness ( $\mathrm{RN}$ ) dimension. The median is higher than the mean with gaps of -1.356 . The standard deviation of the responsiveness dimension is 0.195 , which indicates that the gaps are not widely deviated from the mean. However, the deviation is to the right with a skewness of -1.915 . The gaps are clustered at a point different from the mean of the distribution with a kurtosis value of -5.078 .

\section{Assurance-AS}

The mean gap for the assurance (AS) dimension is -1.365 ; the median gap for this dimension is -1.356 , and it is lower than the mean. The standard deviation is 0.195 , showing little deviation from the mean, which is spread to the right as the distribution is skewed with a value of -1.915 , and the gaps are clustered at some point away from the mean with a kurtosis value of -5.078 .

\section{Empathy-EM}

The mean gap score for the empathy (EM) dimension is -3.214 , while the median gap for this distribution is -1.735 . The standard deviation of the gap score dimension is 0.1114 , which means that the gaps are deviated from the mean. They have deviated toward the right because the distribution is skewed with a value of -1.3324 and are clustered away from the mean, with a kurtosis value of -2.094 . The expectation is higher than the service encountered for this dimension.

\section{Product-PR}

The product (PR) dimension of the airport service quality gap score is -1.67 , indicating that for airport service quality operations sampled in the Nigerian airports, passengers are not satisfied with the services. The median gap score shows a value of -1.67 . The standard deviation is 0.2797 , which means that the gaps have deviated from the mean. The deviation is to the right because the 
Table 3

Descriptive statistics for $O S Q$ - overall service quality of Nigerian airports.

\begin{tabular}{lc}
\hline OSQ-overall service quality & $\mathbf{1 4 2}$ \\
\hline N statistics & 142 \\
Minimum & -2.25 \\
Maximum & 1.13 \\
Mean statistics & -1.8179 \\
Std deviation & 0.32005 \\
Skewness statistics & -1.705 \\
Skewness std error & 0.203 \\
Kurtosis statistics & -6.325 \\
Kurtosis std error & 0.404 \\
\hline
\end{tabular}

distribution is skewed with a value of -2.253 and clustered around a value other than the mean. The kurtosis value is -6.2215 ; for this dimension, the passenger expectation was greater than the service offered. Furthermore, Table 3 shows the descriptive statistics of the overall service quality of Nigerian airports during the study period.

Table 3 shows the descriptive statistics of the overall service quality of Nigerian airports. The result reveals that passengers expect more from the airport service operators in Nigerian airports, evident from the negative mean of -1.8179 , indicating that passengers' expectations exceed perceptions. The respondents' overall level of service quality shows that the standard deviation is 0.32005 , much lower than when we attempted to work with individual service dimensions, and it confirms that there is homogeneity among the sampled population. The deviation gap is more to the right, because the distribution is skewed with a value of -1.705 and the gaps are clustered at some point away from the mean. The standard deviations of individual dimensions are around a common average making them consistent with the six specified service dimensions, and this suggests a range of opinions about the service quality among the passengers surveyed (Daniel \& Berinyuy, 2010). Furthermore, the overall perceived service quality of the Nigerian airports is low with a value of -1.8179 , meaning that the level of service that passengers received is lower than what they expected. This simply means that there is zero satisfaction in the overall level of service quality offered by the airport operators in Nigeria. This may probably be because of a low quality of service encountered by the airport operators during the study period (Nwaogbe et al., 2017c; Pius et al., 2017a).

The analysis measured airline passengers' expectations and perceptions using a Likert scale, whereby higher numbers indicate a higher level of expectation or perception. The airline expectation and perception of this analysis is an aggregate result of all the airlines operating in Nigeria based on domestic travel operations at airports. Generally, consumer expectation exceeded the perceived level of service shown by the perception scores.

\subsection{Nigeria Airline Customer Perception and Expectation Mean Gap Scores}

These results showed a negative gap score (perception minus expectation). Parasuraman et al. (1988) studied consumer satisfaction. Their study shows how common consumers' expectation exceeds the actual service perceived and this signified that there is always a need for improvement. The services of the airlines with the highest expectation scores of 6.7 (TA1) with the question that ideal airline should have modern airplanes and equipment. The second highest expectation gap is on the question that airline employees should be well dressed and appear neat (TA3), showing a score of 6.54 and RL5 shows a score of 6.54. The services provided by airlines should be of good quality (PR2), with a score of 6.53, while several expectations like RN4 were scored from 6.34 and below on expectations such as employees of airlines should never be too busy to respond to passengers' requests, so that when any passenger encounters any problem and calls on the employees, they should respond to them in a holistic way. Furthermore, passengers should feel safe in their encounters with employees. Service fare and quality should be affordable during peak and off-peak hours, and employees should be prompt in service delivery to passengers. The remaining scores of the expectations are shown in Table 4.

However, these scores are not very different from scores of other questions and this implies, generally, that customers expect a very high standard from the airline operators. Because, if passengers are not treated fairly, they might shift their demand to other airline operators and this may bring high competition amongst the airlines. In the case of perception, the questions rated highest for actual services perceived were that airlines kept their passenger records accurately (RL5), attracting a score of 5.53; the employees of the airlines dressed and appeared neat to attend to customers (TA3), attracting a score of 5.46; the airlines' physical environment appeared neat and clean for passengers to enjoy the ticketing and other services at the airline office (TA4), with a score of 5.43; and the airlines are up-to-date in terms of modern equipment and the aircraft they used for their services during air transport operational services (TA1), with a score of 5.29.

Furthermore, from the gap analysis result, the gap differences between expectation and perception were not much different from the various dimensions; instead, the scores of perceptions are lower than those of expectations. It is absolutely essential to consider the service gap that exists between passenger expectation and perception. The gap scores can be measured with a range of values between -6 and +6 (service quality and customer satisfaction). When the airline perception becomes close to expectation, this implies that the higher the perceived level of quality, the more likely the customer will demand or choose to use 
Table 4

Summary of airline customers' mean gap scores.

\begin{tabular}{lcccc}
\hline Dimension & Statement & Expectation score & Perception score & Gap score \\
\hline Tangibility & TA1 & 6.7 & 5.29 & -1.41 \\
& TA2 & 6.13 & 4.97 & -1.16 \\
& TA3 & 6.54 & 5.43 & -1.08 \\
Reliability & TA4 & 6.6 & 4.8 & -1.17 \\
& RL1 & 6.13 & 4.87 & -1.33 \\
& RL2 & 6.32 & 4.77 & -1.45 \\
& RL3 & 6.12 & 4.89 & -1.35 \\
Responsiveness & RL4 & 6.17 & 5.53 & -1.01 \\
& RL5 & 6.54 & 4.78 & -1.05 \\
& RN1 & 5.83 & 5.07 & -0.96 \\
Assurance & RN2 & 6.03 & 4.99 & -0.97 \\
& RN3 & 5.96 & 5.11 & -1.23 \\
RN4 & 6.34 & 4.93 & -1.18 \\
Empathy & AS1 & 6.11 & 5.05 & -1.25 \\
& AS2 & 6.3 & 4.67 & -1.5 \\
PS3 & 6.17 & 4.74 & -0.95 \\
& AS4 & 5.96 & 4.5 & -1.12 \\
& EM1 & 5.62 & 4.58 & -1.19 \\
& EM2 & 5.69 & 4.73 & -1.32 \\
& EM3 & 5.92 & 4.79 & -1.2 \\
& EM4 & 6.11 & 4.77 & -1.29 \\
\hline
\end{tabular}

Note. Average airline quality-of-service gap: -1.3243 .

the airline. This study shows various large gap scores of airline service quality. The result shows that when passengers have problems, the airline shows sincere interest in solving such problems (RL2) with a gap score of -1.45 . The Nigerian airlines have to update with modern equipment and the aircraft they use for air transport services (TA1) with a gap score of -1.41 . The airlines perform their service rightly, as in their services are efficient (RL3) with a gap score of -1.35 . If an airline promises to do anything for customers, it always fulfills these promises (RL1) with a gap score of -1.33 . Finally, with regards to the overall gap score of the airline quality of service (EM4), the gap score is -1.32 , while the Nigerian airlines show an average airline quality-of-service gap score of -1.32 . With this overall gap score of the studied airlines, overall quality of service is low. In general, this means that the response of passengers or customers of the airlines shows that they are expecting more service quality from the airlines in the country.

\subsection{Gap Score Analysis}

Table 5 shows the gap score results for the six dimensions showing the possibility of determining how service users or passengers perceived the quality of the services of the Nigerian airlines in the study area. Moreover, it identifies service dimensions that show how satisfied the passengers are with airline services in Nigeria. Arguments were made by scholars (Parasuraman et al.,
1985; Pius et al., 2017b) that the higher the scale of positive perception $(\mathrm{P})$, the lower the scale of a minus expectation score. Which means the higher the perceived service quality the higher the level of customer satisfaction for the services offered by the providers. The gap scores for this study are based on the differences between the service users' perceptions and expectations. The researchers observed that airline passengers' perceptions of the service quality offered by the Nigerian airline operators fell short of their expectations (gap score dimensions were mostly negative). Besides, the six dimensions' descriptive statistics were used in measuring the gap score assessment. The highest mean gap scores were empathy with a score of -1.88 , followed by product service with a score of -1.3 , and reliability of the service with an average score of -1.284 . While the lowest mean gap scores were responsiveness at a score of -1.0525 , tangibility with average gap score of -1.205 , and assurance with average gap score of -1.22 . A summary of gap score analysis shows that the perceived service quality is less than passengers' expectations in the Nigerian airline service operations.

Parasuraman et al. (1988) argued that the overall service quality can be measured by obtaining an average gap score of the SERVQUAL dimensions. Furthermore, to measure overall service quality efficiently as perceived by the passengers of various Nigerian airlines, six dimensions of the SERVQUAL model were used to assess an optimum service for the airlines in Nigeria. The management and 
Table 5

Descriptive statistics for airline quality of service for the six dimensions.

\begin{tabular}{|c|c|c|c|c|c|c|}
\hline & $\begin{array}{c}\text { Average gap } \\
\text { score } \\
\text { for tangibility }\end{array}$ & $\begin{array}{l}\text { Average gap } \\
\text { score for } \\
\text { reliability }\end{array}$ & $\begin{array}{l}\text { Average gap score } \\
\text { for responsiveness }\end{array}$ & $\begin{array}{l}\text { Average gap score } \\
\text { for assurance }\end{array}$ & $\begin{array}{c}\text { Average gap } \\
\text { score for empathy }\end{array}$ & $\begin{array}{c}\text { Average gap } \\
\text { score for product }\end{array}$ \\
\hline Mean & -1.205 & -1.284 & -1.0525 & -1.22 & -1.88 & -1.3 \\
\hline Median & -1.12 & -1.36 & -0.965 & -1.375 & -1.206 & -1.3 \\
\hline Std deviation & 0.897 & 0.7062 & 0.52275 & 0.6275 & 0.4494 & 0.8295 \\
\hline Skewness & -1.87325 & -1.398 & -0.9055 & -1.07718 & -1.101 & -1.3345 \\
\hline Std error of skewness & 0.215 & 0.215 & 0.215 & 0.215 & 0.215 & 0.215 \\
\hline Kurtosis & -6.4815 & -4.6202 & -2.304 & -3.15525 & -1.3349 & -3.1995 \\
\hline Std error of kurtosis & 0.427 & 0.427 & 0.427 & 0.427 & 0.427 & 0.427 \\
\hline
\end{tabular}

alignment with the findings of Gronroos (1982), who proposed two main dimensions of service quality, technical and product dimensions, were added to the modified SERVQUAL model to reflect the technical dimension of service quality. The model is appropriate for measuring service quality in the airline industry, regarding the fact that service quality offered by airline or carrier operators in Nigeria forms part of the core reason for passengers' satisfaction and continuing patronage decision making during operation. Table 5 shows the standard deviation scores, distributed and consistent with the six dimensions. This suggested a wide range of opinions about the service quality among the respondents surveyed in this study (Pius et al., 2017a).

\subsubsection{Service Constants of the Airlines}

Table 5 shows the service constants of the airlines for the various dimensions of the SERVQUAL model used for the analysis. The analysis is as follows.

\section{Tangibility-TA}

With regards the tangibility, the mean score is -1.205 with a median gap score of -1.12 , while the standard deviation of the gap score is 0.897 , indicating the spread of gap scores away from the mean. This dimension has the highest standard deviation, but it does show great deviation from the mean. The distribution is positively skewed with a value of -1.873 , which indicates that the scores have deviated more to the right. The kurtosis value is -6.4815 , which means that there is clustering somewhat away from the mean. This implies that the service users expected more than what they are getting from the airline service providers.

\section{Reliability-RL}

Regarding the reliability of service, the result shows a mean gap score of -1.284 , which means that passengers are not satisfied with the quality of services rendered from the reliability service dimension. It shows a standard deviation of about 0.7062 , which means that the gap scores are spread away from the mean. The median gap score for the reliability of service is -1.36 . The gap distribution is positively skewed with a value of -1.398 , indicating that the gaps scores are deviated towards the right at the mean, and clustered close to the mean with a kurtosis value of -4.6202 .

\section{Responsiveness-RN}

On average, passengers are somewhat satisfied with the level of services offered by the airline operators, with a gap score of -1.0525 for the responsiveness dimension. The median is lower than the mean with a service gap score of -0.965 . The standard deviation of the responsiveness dimension gap score is 0.52275 , which indicates that the gaps are not widely deviated from the mean. However, the deviation is to the right with a skewness gap score of -0.9055 . The gaps are clustered at a point different from the mean of the distribution with a kurtosis value of -2.304 .

\section{Assurance-AS}

The mean gap for the assurance dimension is -1.22 ; the median is higher than the mean with a service gap score of -1.375 . The standard deviation of the gap score is 0.6275 , showing little deviation from the mean, which is spread to the right as the distribution is skewed with a value of -1.07718 , and the gaps are clustered at some point away from the mean with a kurtosis value of -3.155 .

\section{Empathy-EM}

The mean gap score for the empathy dimension is -1.88 , while the median gap for this distribution is -1.206 . The standard deviation of the gap score dimension is 0.4494 , which means that the gaps have deviated from the mean. They have deviated toward the right because the distribution is skewed with a value of -1.101 and clustered away from the mean, with a kurtosis value of -1.3349 . The expectation is higher than the service encountered for this dimension.

\section{Product services-SE}

The service dimension of the airline service quality gap score is -1.3 , indicating that for airline service quality operations sampled in the Nigerian airlines, passengers are not satisfied with the services. The median gap score shows a value of -1.3 which is the same as the mean. 
The standard deviation of the score is 0.8295 , which means that the gaps have deviated from the mean. The deviation is to the right because the distribution is skewed with a value of -1.3345 and clustered around a value other than the mean. The kurtosis value is -3.1995 in this dimension. The passengers' expectations were greater than the services offered. Furthermore, Table 6 shows the descriptive statistics of the overall service quality of Nigerian airports during the study period.

Table 6 shows that passengers expect more from the airline service operators in Nigeria, evident from the negative mean of -1.3243 , indicating that passengers' expectations exceed perceptions. The respondents' overall level of service quality shows a standard deviation of

Table 6

Descriptive statistics for $O S Q$ - overall service quality of Nigerian airlines.

\begin{tabular}{lc}
\hline OSQ-overall service quality & $\mathbf{1 2 7}$ \\
\hline N statistics & 127 \\
Minimum & -1.5 \\
Maximum & -0.95 \\
Mean statistics & -1.3243 \\
Std deviation & 0.6721 \\
Skewness statistics & 1.2816 \\
Skewness std. error & 0.215 \\
Kurtosis statistics & -3.516 \\
Kurtosis std error & 0.427 \\
\hline
\end{tabular}

0.6721. This is much lower than when we attempted to work with individual service dimensions, and it confirms that there is homogeneity among the sampled population. The deviation gap is more to the right because the distribution is skewed with a value of 1.2816 and the gaps are clustered at some point away from the mean. Standard deviations of individual dimensions are around a common average, making them consistent with the six specified service dimensions, suggesting a range of opinions about the service quality among the passengers surveyed (Daniel \& Berinyuy, 2010). Furthermore, the overall perceived service quality of the Nigerian airlines is low with a value of -1.3243 , meaning that the level of service that passengers received is lower than what they expected. This simply means that there is zero satisfaction in the overall level of service quality offered by the airline operators in Nigeria. This may probably be because of the low quality of service provided by the airline operators during the study period (Pius et al., 2017a).

\subsection{Factor Analysis for the Difference Between Perceptions and Expectations (Gap Scores)}

\subsubsection{Factor Analysis of Airport Quality of Service Expectation}

Table 7 shows the factor analysis result of the airports in Nigeria, during the study period. Factor analysis is used

Table 7

Rotated component matrix ${ }^{a}$ of airports' quality of service expectation.

\begin{tabular}{|c|c|c|c|c|c|c|c|}
\hline & \multicolumn{7}{|c|}{ Component } \\
\hline & 1 & 2 & 3 & 4 & 5 & 6 & 7 \\
\hline TA4 & 0.825 & & & & & & \\
\hline TA3 & 0.790 & 0.302 & & & & & \\
\hline TA2 & 0.773 & 0.302 & & & 0.331 & & \\
\hline TA1 & 0.770 & 0.358 & & & & & \\
\hline RL2 & 0.752 & 0.333 & & & & 0.333 & \\
\hline RL1 & 0.687 & 0.485 & & & & & \\
\hline RL3 & 0.564 & 0.470 & & & & 0.393 & \\
\hline PR2 & 0.497 & 0.483 & & & 0.464 & & \\
\hline AS3 & & 0.855 & & & & & \\
\hline EM4 & 0.321 & 0.698 & & & & & \\
\hline AS1 & 0.465 & 0.684 & 0.313 & & & & \\
\hline RN1 & 0.448 & 0.669 & & & & 0.303 & \\
\hline AS4 & 0.331 & 0.664 & & 0.355 & & & 0.355 \\
\hline PR1 & 0.400 & 0.644 & & 0.301 & & & \\
\hline RN2 & 0.522 & 0.638 & & & & 0.307 & \\
\hline AS2 & 0.413 & 0.572 & & 0.366 & 0.445 & & \\
\hline RN3 & 0.306 & & 0.805 & & & & \\
\hline EM2 & & 0.377 & 0.642 & & & & \\
\hline EM3 & & & & 0.851 & & & \\
\hline EM5 & 0.335 & 0.547 & & 0.586 & & & \\
\hline RL5 & 0.472 & 0.365 & & & 0.571 & & \\
\hline RN4 & 0.373 & 0.310 & 0.401 & & 0.566 & & \\
\hline RL4 & 0.385 & 0.338 & & & 0.325 & 0.645 & \\
\hline EM1 & & 0.396 & & & & & 0.665 \\
\hline
\end{tabular}

Note. Extraction method: principal component analysis. Rotation method: Varimax with Kaiser normalization.

${ }^{\text {a }}$ Rotation converged in 7 iterations. 
mostly for data deduction reasons during analysis and is performed by examining the pattern of correlations between the observed measures during the study. Factor analysis measures data that are highly correlated during analysis, either positive or negative factors that are likely to influence the study in question. Data that are relatively uncorrelated are likely influenced by different factors (DeCoster, 1998). Factor analysis is of two forms: exploratory factor analysis, which tries to find the nature of the constructs influencing a set of responses; and confirmatory factor analysis, which tests whether a specified set of constructs is influencing responses in a predicted way (DeCoster, 1998). In our study, we use confirmatory factor analysis, because we know already the number of dimensions.

Table 7 shows the factor loadings for each item in relation to the various factors. These values in the table show the weight and correlation that each item has to a factor or component. All values below 0.45 from Table 7 are the parameter load, which is not significant for analysis.

The results of the Kaiser-Meyer-Olkin (KMO) test and Bartlett's test of the airports' quality of service are shown in Table 8 . The KMO test results vary between 0 and 1 , and a value of 0 shows that the sum of partial correlations is large, relative to the sum of correlations. This means that factor analysis is likely to be irrelevant. In contrast, a value close to 1 shows that patterns of correlations are relatively compact and factor analysis yields distinct and reliable factors (Field, 2005). For our case, the value is 0.959, which indicates that factor analysis is relevant for our study because the value is close to $100 \%$. This analysis is based on the common factor model, which proposes that each observed response is influenced by underlying common factors (factors 1, 2, 3, 4, 5, 6, 7) for the airports. This factor is defined as the natural affinity of an item for a group (van der Wal et al., 2002). The strength of the link between each factor and each measure varies, in that a factor could influence some dimensions more than others (DeCoster, 1998). A score below 0.45 indicates a weak loading and is therefore of little or no significance. Factor loadings are the weights and correlations between each variable and the factor. The higher the load, the more important it is in defining the factor's dimensionality. A negative value indicates an inverse impact on the factor.

Table 9 shows how much of the total data fit into the four factors and this is carried out using variance. The total variance accumulated in the five factors is $88.618 \%$ and

Table 8

KMO and Bartlett's test of airports' quality of service expectation.

\begin{tabular}{lcc}
\hline KMO measure of sampling adequacy & $\mathbf{0 . 9 5 9}$ \\
\hline Bartlett's test of sphericity & Approx. chi-square & 4520.109 \\
& Df & 276 \\
Sig. & 0.000 \\
\hline
\end{tabular}

factor 1 carries $71.447 \%$ of data indicating that the data fit into the factor. This means that inadequate policy on quality of service (dimensions such as tangibility, reliability, responsiveness, assurance, empathy, and product) can lead to poor-quality service at airports. If the factors are addressed very well, this can mean that the airports have the best standard of such factors to attract more passengers due to good service quality. The other factors carry above $10 \%$ each and show somewhat a fit of data in the factors. While the remaining factors were below $10 \%$, showing that those ones are relatively low fit of data in the factors.

\subsubsection{Factor Analysis of Airline Quality of Service Perception}

Table 10 shows the result of the factor analysis of the airlines in Nigeria during the study period. Factor analysis is used mostly for data deduction reasons during analysis and is performed by examining the pattern of correlations between the observed measures during the study. Factor analysis measures data that are highly correlated during analysis, either positive or negative factors that are likely to influence the study matter in question. In contrast, those that are relatively uncorrelated are likely influenced by different factors (DeCoster, 1998). Factor analysis is of two forms: exploratory factor analysis, which tries to find the nature of the constructs influencing a set of responses; and confirmatory factor analysis, which tests whether a specified set of constructs is influencing responses in a predicted way (DeCoster, 1998). In our study, we use confirmatory factor analysis because we know already the number of dimensions.

The results of the KMO test and Bartlett's test of the airlines' quality of service are shown in Table 10. The KMO test results vary between 0 and 1 and a value of 0 shows that the sum of partial correlations is large relative to the sum of correlations, meaning that factor analysis is likely to be irrelevant. A value close to 1 shows that patterns of correlations are relatively compact and factor analysis yields distinct and reliable factors (Field, 2005). For our case, the value is 0.957 , which indicates that factor analysis is relevant for our study because the value is close to $100 \%$. This analysis is based on the common factor model, which proposes that each observed response is influenced by underlying common factors (factors 1, 2, 3, $4,5,6,7)$ for the Nigerian airlines. This factor is defined as the natural affinity of an item for a group (Van der Wal et al., 2002). The strength of the link between each factor and each measure varies in that a factor could influence some dimensions more than others (DeCoster, 1998). A score below 0.45 indicates a weak loading and is therefore of little or no significance. Factor loadings are the weights and correlations between each variable and the factor. The higher the load, the more important it is in defining the factor's dimensionality. A negative value indicates an inverse impact on the factor. 
Table 9

Total variance explained of airports' quality of service expectation.

\begin{tabular}{|c|c|c|c|c|c|c|}
\hline \multirow[b]{2}{*}{ Component } & \multicolumn{3}{|c|}{ Initial eigenvalues } & \multicolumn{3}{|c|}{ Rotation sums of squared loadings } \\
\hline & Total & $\%$ of Variance & Cumulative \% & Total & $\%$ of Variance & Cumulative $\%$ \\
\hline 1 & 17.147 & 71.447 & 71.447 & 6.299 & 26.246 & 26.246 \\
\hline 2 & 1.129 & 4.703 & 76.150 & 5.935 & 24.730 & 50.976 \\
\hline 3 & 0.981 & 4.087 & 80.236 & 2.301 & 9.588 & 60.564 \\
\hline 4 & 0.608 & 2.534 & 82.770 & 2.250 & 9.373 & 69.937 \\
\hline 5 & 0.504 & 2.100 & 84.870 & 1.979 & 8.246 & 78.182 \\
\hline 6 & 0.470 & 1.960 & 86.830 & 1.307 & 5.446 & 83.629 \\
\hline 7 & 0.429 & 1.788 & 88.618 & 1.197 & 4.989 & 88.618 \\
\hline 8 & 0.354 & 1.476 & 90.093 & & & \\
\hline 9 & 0.310 & 1.293 & 91.387 & & & \\
\hline 10 & 0.252 & 1.051 & 92.437 & & & \\
\hline 11 & 0.245 & 1.020 & 93.457 & & & \\
\hline 12 & 0.237 & 0.986 & 94.443 & & & \\
\hline 13 & 0.212 & 0.883 & 95.326 & & & \\
\hline 14 & 0.190 & 0.793 & 96.120 & & & \\
\hline 15 & 0.151 & 0.629 & 96.749 & & & \\
\hline 16 & 0.144 & 0.600 & 97.349 & & & \\
\hline 17 & 0.135 & 0.561 & 97.910 & & & \\
\hline 18 & 0.112 & 0.467 & 98.376 & & & \\
\hline 19 & 0.100 & 0.416 & 98.792 & & & \\
\hline 20 & 0.093 & 0.387 & 99.179 & & & \\
\hline 21 & 0.076 & 0.316 & 99.495 & & & \\
\hline 22 & 0.052 & 0.217 & 99.713 & & & \\
\hline 23 & 0.037 & 0.156 & 99.868 & & & \\
\hline 24 & 0.032 & 0.132 & 100.000 & & & \\
\hline
\end{tabular}

Table 10

KMO and Bartlett's test of airline quality of service perception.

\begin{tabular}{lcc}
\hline KMO measure of sampling adequacy & $\mathbf{0 . 9 5 7}$ \\
\hline Bartlett's test of sphericity & Approx. chi-square & 3492.978 \\
& Df & 276 \\
& Sig. & 0.000 \\
\hline
\end{tabular}

Table 11 shows the factor loadings of Nigerian airlines for each item in relation to the various factors. These values in the table show the weight and correlation each item has to a factor or component. All values below 0.45 from Table 11 are the parameter load that is not significant for analysis.

Furthermore, Table 12 shows how much of the total data fit into the four factors and this is carried out using variance during the analysis of the airlines using factor analysis. The total variance accumulated in the seven factors is $86.230 \%$ and factor 1 carries $69.627 \%$ of data indicating that the data fit into the factor. This means that inadequate policy on quality of service (dimension such as tangibility, reliability, responsiveness, assurance, empathy, and product) can lead to poor-quality service of the airlines. If the factors are addressed very well, this can mean that the airlines have the best standard of such factors to attract more passengers due to good service quality. The other factors carry above $10 \%$ each and show relative fit of data in the factors. While the remaining factors were below 10\%, showing that those ones are relatively low fit of data in the factors.

\section{Conclusion}

The overall gap score of the selected Nigerian airports shows that there is an average gap score of -1.8179 for overall airport quality of service. This reveals that the perceived service quality is less than passengers' expectations for the selected Nigerian airport service operations. Thus, the level of service that passengers received is lower than what they expected. In the same vein, the gap score of the selected Nigerian airlines shows that there is an average gap score of -1.32 for the overall airline quality of service and the value is generally low. This means that the response of passengers or customers of the airlines and the airports during the study period reveals that they are expecting better service quality from the airlines and the airports in the country. Hence, inadequate policy on quality of service (in terms of tangibility, reliability, responsiveness, assurance, empathy, and product) can lead to poor service quality of airlines and at airports. These factors should be addressed very well so that airport and airline operators can attain the best standards to attract more passengers. The selected airports and airlines need to upgrade their operational standards so as to have an optimal overall quality of service and level of service. Finally the level of service needs to be improved so as to satisfy passengers' 
Table 11

Rotated component matrix ${ }^{a}$ of airline quality of service perception.

\begin{tabular}{|c|c|c|c|c|c|c|c|}
\hline & \multicolumn{7}{|c|}{ Component } \\
\hline & 1 & 2 & 3 & 4 & 5 & 6 & 7 \\
\hline RL5 & 0.712 & 0.361 & & & & & \\
\hline TA4 & 0.711 & 0.342 & 0.319 & & & & \\
\hline TA1 & 0.705 & & & 0.366 & & & \\
\hline TA4 & 0.669 & 0.422 & & & & & \\
\hline PR2 & 0.556 & 0.488 & & & & 0.300 & \\
\hline EM5 & 0.542 & & 0.333 & & 0.345 & 0.518 & \\
\hline AS2 & 0.479 & 0.359 & 0.441 & 0.340 & & & 0.364 \\
\hline PR1 & 0.468 & & & 0.397 & & 0.444 & 0.334 \\
\hline RL4 & & 0.694 & 0.332 & & 0.302 & & \\
\hline RL1 & 0.331 & 0.647 & & 0.424 & & & \\
\hline RL3 & & 0.616 & & 0.319 & & 0.344 & \\
\hline RL2 & 0.348 & 0.601 & 0.324 & 0.343 & & & 0.341 \\
\hline RN1 & 0.381 & 0.591 & 0.426 & & 0.347 & & \\
\hline AS4 & & 0.500 & 0.441 & & 0.320 & 0.372 & \\
\hline AS3 & & & 0.693 & & & 0.312 & \\
\hline AS1 & 0.364 & 0.349 & 0.616 & 0.300 & & & \\
\hline RN3 & 0.346 & 0.337 & 0.409 & 0.615 & & & \\
\hline RN2 & 0.312 & & 0.442 & 0.589 & & & \\
\hline RN4 & 0.432 & & & 0.563 & & & 0.432 \\
\hline TA2 & 0.458 & 0.390 & & 0.503 & 0.317 & & \\
\hline EM1 & & & & & 0.777 & & \\
\hline EM2 & & 0.370 & & & 0.761 & & \\
\hline EM4 & 0.313 & 0.302 & & & & 0.746 & \\
\hline EM3 & 0.301 & & & & 0.314 & & 0.780 \\
\hline
\end{tabular}

Note. Extraction method: principal component analysis. Rotation method: Varimax with Kaiser normalization.

${ }^{\mathrm{a}}$ Rotation converged in 13 iterations.

Table 12

Total variance explained of airline quality of service perception.

\begin{tabular}{|c|c|c|c|c|c|c|c|c|c|}
\hline \multirow[b]{2}{*}{ Component } & \multicolumn{3}{|c|}{ Initial eigenvalues } & \multicolumn{3}{|c|}{ Extraction sums of squared loadings } & \multicolumn{3}{|c|}{ Rotation sums of squared loadings } \\
\hline & Total & $\begin{array}{c}\% \text { of } \\
\text { Variance }\end{array}$ & Cumulative $\%$ & Total & $\begin{array}{c}\% \text { of } \\
\text { Variance }\end{array}$ & Cumulative $\%$ & Total & $\begin{array}{c}\% \text { of } \\
\text { Variance }\end{array}$ & Cumulative $\%$ \\
\hline 1 & 16.711 & 69.627 & 69.627 & 16.711 & 69.627 & 69.627 & 4.674 & 19.475 & 19.475 \\
\hline 2 & 0.988 & 4.115 & 73.742 & .988 & 4.115 & 73.742 & 4.040 & 16.834 & 36.309 \\
\hline 3 & 0.792 & 3.301 & 77.044 & 0.792 & 3.301 & 77.044 & 2.771 & 11.547 & 47.855 \\
\hline 4 & 0.670 & 2.791 & 79.834 & 0.670 & 2.791 & 79.834 & 2.710 & 11.292 & 59.147 \\
\hline 5 & 0.600 & 2.501 & 82.335 & 0.600 & 2.501 & 82.335 & 2.607 & 10.863 & 70.010 \\
\hline 6 & 0.505 & 2.106 & 84.441 & 0.505 & 2.106 & 84.441 & 2.144 & 8.932 & 78.942 \\
\hline 7 & 0.429 & 1.789 & 86.230 & 0.429 & 1.789 & 86.230 & 1.749 & 7.288 & 86.230 \\
\hline 8 & 0.386 & 1.609 & 87.838 & & & & & & \\
\hline 9 & 0.331 & 1.378 & 89.216 & & & & & & \\
\hline 10 & 0.290 & 1.210 & 90.425 & & & & & & \\
\hline 11 & 0.280 & 1.166 & 91.591 & & & & & & \\
\hline 12 & 0.268 & 1.117 & 92.709 & & & & & & \\
\hline 13 & 0.228 & 0.948 & 93.657 & & & & & & \\
\hline 14 & 0.220 & 0.916 & 94.573 & & & & & & \\
\hline 15 & 0.215 & 0.896 & 95.469 & & & & & & \\
\hline 16 & 0.190 & 0.790 & 96.259 & & & & & & \\
\hline 17 & 0.174 & 0.726 & 96.985 & & & & & & \\
\hline 18 & 0.141 & 0.586 & 97.572 & & & & & & \\
\hline 19 & 0.136 & 0.567 & 98.139 & & & & & & \\
\hline 20 & 0.109 & 0.455 & 98.594 & & & & & & \\
\hline 21 & 0.101 & 0.421 & 99.014 & & & & & & \\
\hline 22 & 0.094 & 0.391 & 99.406 & & & & & & \\
\hline 23 & 0.077 & 0.321 & 99.727 & & & & & & \\
\hline 24 & 0.066 & 0.273 & 100.000 & & & & & & \\
\hline
\end{tabular}

Note. Extraction method: principal component analysis. 
expectations at airports. Policy implications are made from the study based on the findings of the overall quality of service from analysis of six dimensions (tangibility, reliability, responsiveness, assurance, empathy, and product), determining the factors that are weak, and improving them to have an efficient and effective level of service and quality at the selected airports. The study results will enhance stakeholder and airport management on how to manage customers in terms of customer relation and satisfaction, because, if well managed, will yield a large market share and good market competition in the aviation industry.

\section{References}

Airport Council International. (2014). Airport-Service-Quality/AboutASQ. Retrieved from http://www.aci.aero/Airport-Service-Quality/ ASQ-Home.

Chao, C. C., Lin, H. C., \& Chen, C. Y. (2013). Enhancing airport service quality: A case study of Kaohsiung International Airport. Paper presented at the Eastern Asia Society for Transportation Studies.

Chilembwe, J. M. (2014). Evaluation of service quality, value and satisfaction of air transportation in Malawi: Case study of Air Malawi. International Journal of Social Sciences and Entrepreneurship, 1(11), 236-266.

Cronin, J.J., \& Taylor, S.A. (2011). Measuring service quality: A reexamination and extension. Journal of Marketing, 56(3), 55-68. http://dx.doi.org/10.2307/1252296

Daniel, C. N., \& Berinyuy, L. P. (2010). Using the SERVQUAL model to assess service quality and customer satisfaction: An empirical study of grocery store [Master's thesis]. Umea University.

Decoster, J. (1998). Overview of factor analysis. Retrieved 29 April, 2012, from http://www.sta-help.com

Demuren, H. (2017). Why aviation sector remains at infancy 91 years on-Business-The Guardian Nigeria. Retrieved from http://guardian. ng/business-services/aviationbusiness/why-aviation-sector-remains-atinfancy-91-years-on/

Field, A. P. (2005). Discovering statistics using SPSS (2nd ed.). London: Sage.

Gronroos, C. (1982). A service quality model and its marketing implications. European Journal of Marketing, 18(4), 36-44.

Ikeogu, C. C. (2013). The quality of customer service in Nigeria's International airline industry and its relationship with the level of patronage: Case of Air France and Lufthansa. International Journal of Research in Commerce \& Management, 4(8), 136-144.

International Air Transport Association. (2015). IATA global passenger survey highlights. Retrieved from www.iata.org/publications/Pages/ global-passenger-survey.aspx
Kirk, P. J. (2013). Passenger experience at airports: An activity-centred approach [Doctoral thesis]. Queensland University of Technology.

Kramer, L. S., Bothner, A., \& Spiro, M. (2013). How airports measure customer service performance. Washington, DC: Transportation Research Board.

Kumar, M., Kee, F. T., \& Manshor, A. T. (2009). Determining the relative importance of critical factors in delivering service quality of banks: An application of dominance analysis in the SERVQUAL model. Managing Service Quality, 19(2), 211-228.

Nwaogbe, O. R., Ogwude, I. C., \& Ibe, C. C. (2017a). Efficiency analysis of the Nigeria airports: An application of DEA-BCC model. International Scientific Journal of Air Transport Industry (AERO-Journal), 2, 28-39.

Nwaogbe, O. R., Pius, A., Balogun, A. O., Ikeogu, C. C., \& Omoke, V. (2017b). An assessment of airline service quality in a category one nation: Focus on Mallam Aminu Kano International Airport. International Journal of Aviation, Aeronautics, and Aerospace, 4(1), 1-27. Retrieved from http://commons.erau.edu/ijaaa/vol4/iss1/7

Nwaogbe, O. R., Pius, A., Nuhu, L. O., \& Wokilli-Yakubu, H. (2017c). An evaluation of airport operation safety: A case of Nnamdi Azikiwe International Airport (NAIA). Aviation \& Space Journal, 16(1), 2-20.

Nwaogbe, O. R., Wokili, H., Omoke, V., \& Asiegbu, B. (2013). An analysis of the impact of air transport sector to economic development in Nigeria. IOSR Journal of Business and Management, 14(5), 41-48.

Oxford Economics. (2015). Airlines and airports data. Retrieved from http://www.oxfordeconomics.com/airlines-and-airports

Pabedinskaitéa, A., \& Akstinaite, V. (2014). Evaluation of the airport service quality, Procedia Social and Behavioral Sciences, 110, 398-409.

Parasuraman, A., Zeithaml, V. A., \& Berry, L. L. (1985). A conceptual model of service quality and its implications for future research. Journal of Marketing, 49, 41-50.

Parasuraman, A., Zeithaml, V. A., \& Berry, L. L. (1988). SERVQUAL: A multiple-item scale for measuring consumer perceptions of service quality. Journal of Retailing, 64(1), 12-40.

Pius, A., Nwaogbe, O. R., Akerele, U. O., \& Masuku, S. (2017a). Appraisal of airport terminal performance: Murtala Muhammed International Airport (MMIA). International Journal of Professional Aviation Training \& Testing Research, 9(1), 1-27. Retrieved from http://ojs.library.okstate.edu/osu/index.php/IJPATTR/index

Pius, A., Nwaogbe, O. R., \& Manian, C. (2017b). SERVQUAL measurement of commuter perception of rail service: An empirical study of London Zone 1 travelling area. Proceedings of the British Academy of Management (BAM) 2017 Conference, 5-7 September, University of Warwick.

Suzuki, N. M. (2014). Passenger satisfaction with airline service quality in Malaysia: A structural equation modeling approach. Research in Transportation Business \& Management, 10.

Van der Wal, R. W. E., Pampallis, A., \& Bond, C. (2002). Service quality in a cellular telecommunications company: A South African experience. Managing Service Quality, 12(5), 323-335. 